\author{
Case Study
}

\title{
Selection and application of the most suitable method for sustainable utilization of water resources assessment
}

\author{
Xi Yang ${ }^{1}$
}

Received: 10 August 2020 / Accepted: 21 September 2020

(c) The Author(s) 2020 OPEN

\begin{abstract}
Evaluation of the regional sustainable use of water resources (SUWR) is one of the core issues for studying regional sustainable development strategy. In the process of evaluation, it is crucial to select a reasonable and applicable evaluation methods to improve the reliability of evaluation results. In this paper, the index system of SUWR was established by coupling eco-environment, socioeconomic and water utilization system. The dipartite degree theory (DD) and the serial number synthesis theory (SNS) were applied for selecting the suitable sustainability assessment method among six evaluation methods. The selected method was used for analyzing the spatial difference in Fujian Province, China. Results indicated that (1) based on different evaluation methods for the SUWR, the stability and reliability of fuzzy matter-element analysis are higher than those of fuzzy comprehensive evaluation, attribute recognition, improved rank correlation, principal component analysis and grey relation analysis; (2) The regions with a higher level of SUWR are concentrated in the west of the research area, while the eastern regions have a lower level. The highest sustainable level of water resources was 0.647 , in Longyan city and the lowest level was 0.399 , in Xiamen city; (3) The superimposition effects of water resource conditions, topography and economic development level formed the spatial distribution pattern of sustainable utilization level. The results may provide scientific guidance for the effective evaluation of regional SUWR, water resources management and government decision-making.
\end{abstract}

Keywords Water resources · Sustainable utilization $\cdot$ Suitable method $\cdot$ Spatial difference $\cdot$ Fujian province

\section{Introduction}

Water resources are not only the basic elements of the eco-environment, but an important guarantee for social economic development [1]. With the rapid development of socioeconomic and the impact of global climate change, the water resources crisis is more serious than ever [2], it has become key factor to limit social-economic sustainable development [3]. Therefore, it has important practical value for evaluating the SUWR reasonably for realizing regional sustainable development and the virtuous circle of ecosystems [4].

Nowadays, many researchers have conducted a lot of research on the SUWR [5], but there is no unified standard and accepted evaluation method. From the perspective of the structure of the evaluation process of SUWR, complete evaluation research mainly includes five parts: index system construction, evaluation standard determination, data processing, index weight assignment, and evaluation method selection. Among them, it is very important to choose a reasonably applicable evaluation method to improve the reliability of evaluation results [6]. According to the nature and theoretical

Electronic supplementary material The online version of this article (https://doi.org/10.1007/s43621-020-00003-w) contains supplementary material, which is available to authorized users.

Xi Yang, fujyyangxi@163.com | 'School of Civil Engineering, Sun Yat-Sen University, Guangzhou 510275, Guangdong Province, China.

Discover Sustainability $\quad$ (2020) 1:3 Ittps://doi.org/10.1007/s43621-020-00003-w 
basis of the method, the typical evaluation methods can be roughly divided into two categories [7, 8]: (1) Composite index method, it is evaluated in the absence of regional evaluation criteria for the SUWR: such as Principal component analysis(PCA) method [9], Analytic Hierarchy Process method (AHP) [10], Grey Relation Analysis method(GRA) [11]and Improved Rank Correlation method (IRC) [11], etc. (2) Grade evaluation method, it is evaluated under the evaluation criteria for SUWR in a given region. e.g. Fuzzy matter-element method (FME) [12], Fuzzy comprehensive evaluation (FCE) [12], Attribute recognition (AR) [13], Set pair analysis (SPA) [14], etc. These methods have been widely applied to the SUWR. However, the main problem is that the same indicator system is selected for the same evaluation object, and based on the same data, the evaluation results obtained by different evaluation methods are inconsistent. That is to say, it is difficult to determine which evaluation method is suitable for assessing SUWR. This problem has been noticed by some scholars and it necessitates to carry out further research.

Some scholars have done relevant research. Wang et al. performed a water scarcity evaluation using the iterativecorrection approach and found this approach can supply water scarcity with insightful analyses of water scarcity [15]. Jia et al. proposed to convert several evaluation methods into a comprehensive model and apply it to water security evaluation in the Yellow River basin. The results of the integrated model better reflect the water security than the single evaluation model [16]. However, the above research only involves the optimization of the evaluation results, it is still unresolved for selection of suitable assessment method.

Therefore, this paper adopted six common assessment methods (FCE, AR, FME, PCA, IRC and GRA) and used the DD and SNS to select the suitable evaluation method for improving the reliability of regional SUWR assessment, then the suitable method were applied to analyze the spatial differences of regional SUWR. This will provide a reasonable evaluation results for decision-makers.

\section{Materials and methods}

\subsection{Study area and data}

Fujian province $\left(23^{\circ} 33^{\prime}-28^{\circ} 20^{\prime} \mathrm{N}, 115^{\circ} 50^{\prime}-120^{\circ} 40^{\prime} \mathrm{E}\right)$ lies in the southeast of China (Fig. 1), which belongs to subtropical marine climate. The annual average temperature is $15.7-22.4^{\circ} \mathrm{C}$, and the average annual precipitation is $1000-1800 \mathrm{~mm}$. It has nine cities under its jurisdiction. Among them, the total amount of water resources in Xiamen on the coast is only $1.2 \times 10^{5} \mathrm{~m}^{3}$, while the number of Nanping City in the west is as high as $2.92 \times 10^{6} \mathrm{~m}^{3}$. In recent years, the imbalance of economic development, the coastal areas are economically developed, with a

Fig. 1 Location of Fujian Province

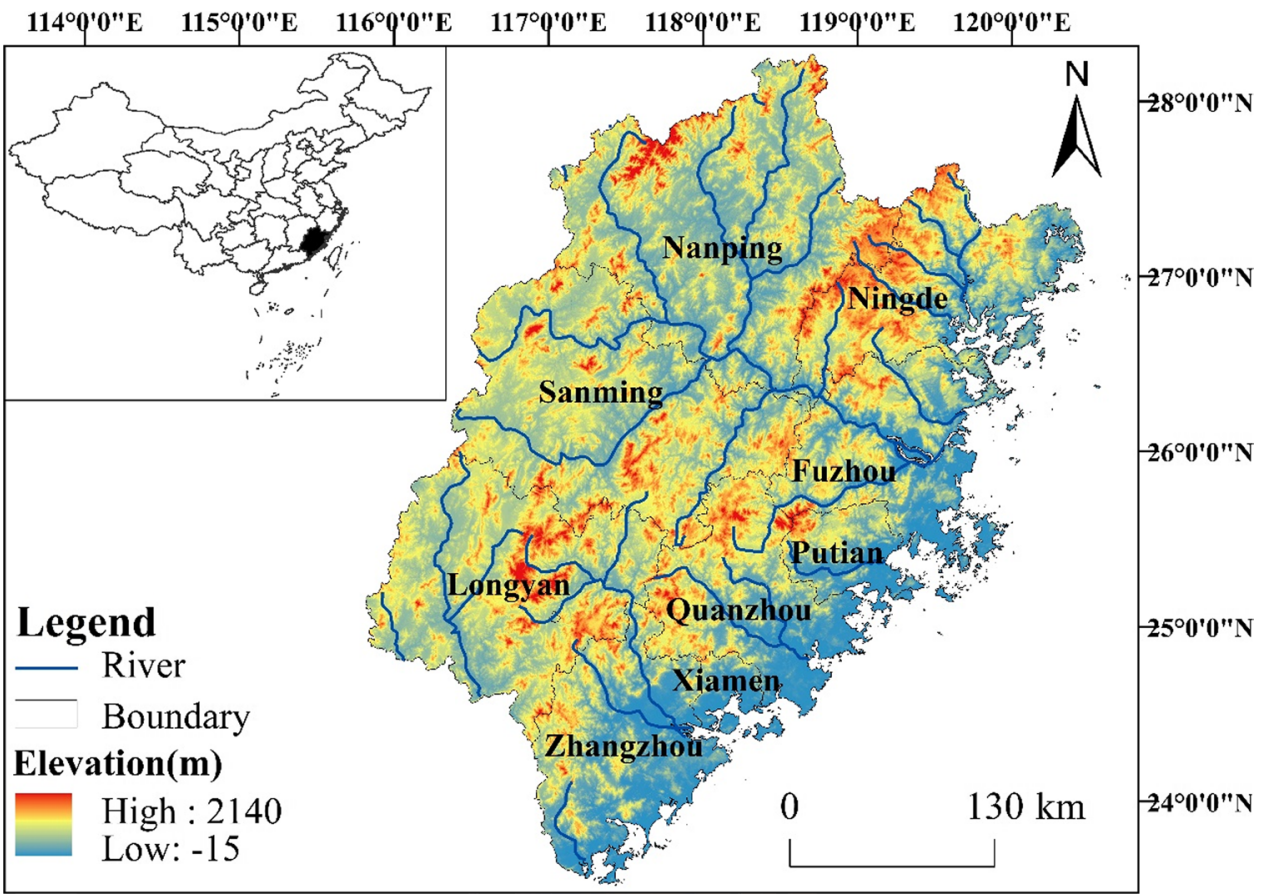


concentrated population and large demand for water resources. The western hilly belt is economically backward, with small population density and low demand for water resources, which has caused the mismatch between the distribution pattern of water resources and economic development in Fujian. To better manage water resources, it is essential for assessing SUWR.

Considering the data accessibility, 2011 was chosen as the evaluation year for analyzing the present situation of SUWR in Fujian. The data used derived from Statistical Bulletin of Fujian Province, for specific information, please refer to [17].

\subsection{Evaluation indicator system}

The construction of an evaluation indicator system that can reflect regional SUWR, which is the basis and premise of the evaluation of SUWR. The construction of this index system should consider various factors affecting SUWR [18, 19]. Therefore, based on the water resources, social, economic, environmental conditions and actual sources of data in Fujian Province, referring to relevant documents $[6,7,12,14,17]$, a total of 12 indicators of water resources have been established in terms of water resources system, development and utilization system, ecological environment and socio-economic system (Table 1). The thresholds of each indicator are shown in Table 2, which corresponds

Table 1 Evaluation index system in Fujian province

Table 2 The evaluation standard in Fujian province

\begin{tabular}{lll}
\hline Criterion layer & Index layer & Unit \\
\hline Water resources system & Water production modulus [17] $X_{11}$ & $10^{4} \mathrm{~m}^{3} / \mathrm{km}^{2}$ \\
& Total water resources [12] $X_{12}$ & $10^{8} \mathrm{~m}^{3}$ \\
& Annual precipitation [17] $X_{13}$ & $\mathrm{~mm}$ \\
Development and utilization system & Reservoir and pond plot ratio per unit area [6] $X_{21}$ & $10^{4} \mathrm{~m}^{3} / \mathrm{km}^{2}$ \\
& Farmland irrigation water consumption [12] $X_{22}$ & $\mathrm{~m}^{3} / \mathrm{km}^{2}$ \\
& Water consumption per ten thousand yuan of & $\mathrm{m}^{3}$ \\
& value-added by industry [17] $X_{23}$ & \\
Ecological environment system & Vegetation coverage rate [12] $X_{31}$ & $\%$ \\
& Urban irrigated green space quota [17] $X_{32}$ & $\mathrm{~m}^{3} / \mathrm{m}^{2}$ \\
& Eco-environmental water use rate [7] $X_{33}$ & $\%$ \\
Socioeconomic system & Water-saving irrigation rate [14] $X_{41}$ & $\%$ \\
& Irrigation rate of cultivated land [6] $X_{42}$ & $\%$ \\
& GDP per capita [12] $X_{43}$ & $10^{4}$ yuan \\
\hline
\end{tabular}

\begin{tabular}{lllll}
\hline Index & \multicolumn{2}{l}{ Evaluation criteria } & & \\
\cline { 2 - 5 } & I & II & III & IV \\
\hline$X_{11}$ & $>150$ & $120-150$ & $90-120$ & $<90$ \\
$X_{12}$ & $>120$ & $90-120$ & $60-90$ & $<60$ \\
$X_{13}$ & $>1800$ & $1500-1800$ & $1200-1500$ & $<1200$ \\
$X_{21}$ & $>30$ & $20-30$ & $10-20$ & $<10$ \\
$X_{22}$ & $<6900$ & $6900-8100$ & $8100-9300$ & $>9300$ \\
$X_{23}$ & $<100$ & $100-200$ & $200-300$ & $>300$ \\
$X_{31}$ & $>70$ & $60-70$ & $50-60$ & $<50$ \\
$X_{32}$ & $>6$ & $4-6$ & $2-4$ & $<2$ \\
$X_{33}$ & $<150$ & $150-250$ & $250-350$ & $>350$ \\
$X_{41}$ & $>0.8$ & $0.65-0.8$ & $0.5-0.65$ & $<0.5$ \\
$X_{42}$ & $>70$ & $60-70$ & $50-60$ & $<50$ \\
$X_{43}$ & $>6$ & $5-6$ & $4-5$ & $<4$ \\
& & & &
\end{tabular}


to the good (I), general (II), early warning (III) and poor (IV). These thresholds are determined by referring to the water-related standard documents and the actual situation in Fujian province [6, 17].

\subsection{Methodology}

The evaluation methods of SUWR mainly include two types: comprehensive index methods and grade type methods. For comprehensive index methods, the IRC and GRA are improved based on AHP, This is because IRC and GRA have accurate algorithms over AHP. PCA is more objective than AHP and it can reflect the value of indicators. Thus, the IRC, GRA and PCA was selected for this study. As for the grading type method, there are different pairs to SPA, and the selection of pairs is influenced by subjective, which may cause the insufficient credibility of results. Because of FCE, AR and FME have their own advantages from different angles, the above three commonly used evaluation methods are selected in this paper: $F C E, A R$ and FME. Therefore, under the same set of evaluation index system, this paper selects FCE, AR, FME, PCA, IRC and GRA for evaluation, and combines the 2 indexes of DD and SNS to obtain the suitable SUWR evaluation method, and then based on the suitable evaluation method to evaluate and grade classification of SUWR in Fujian. Since these evaluation methods have been widely used in the sustainable field of water resources, their respective characteristics can be found $[16,17,20]$. In this paper, the weighting of the index is calculated by AHP, which is a multi-level, multi-objective decisionmaking analysis method with strong logic for solving the analysis of the importance degree between indicators [10].

\subsection{Selection of the suitable evaluation method}

The DD can be used as the reliability index for evaluation results of various evaluation methods [21], and the SNS was used for analyzing the stability of various evaluation methods [22]. Finally, the two indices are used to select the most suitable evaluation method.

\subsubsection{DD method}

The DD can be used as an indicator to judge the reliability of the results of various methods, the greater the DD means the higher reliability and more stability of evaluation results [22]. For the results of the above evaluation methods, supposing that there are $M$ assessment regions and descending order from high to low by its evaluation values $P$; numbering their marks are $N$, then $P=f(N)$ belongs to the monotonous decrease function. The best score for the evaluation result can be written as $\left(P_{1}, 1\right)$ in the coordinate system, and the worst value is $\left(P_{n}, n\right)$; thus the DD is given as:

$$
D=\frac{\sum_{i=1}^{n-1} \sqrt{\left(P_{i+1}-P_{i}\right)^{2}+\left(N_{i+1}-N_{i}\right)^{2}}}{\sqrt{\left(P_{1}-P_{n}\right)^{2}+\left(N_{n}-N_{1}\right)^{2}}}
$$

In the formula (1), $n$ represents the evaluation regions. $D \geq 1$, and when $D$ is larger, it indicates that the adjacent points become more dispersed, the assessment results can be distinguished easier.

Due to the different range of values for various assessment results, this paper normalizes the evaluation outcomes and sets the score between 0 and $m$. The calculation formula is as follows:

$$
V_{i}=n \times\left[1-\frac{\left|V_{i}^{\prime}-V_{1}^{\prime}\right|}{V_{1}^{\prime}-V_{n}^{\prime}}\right]
$$

where, $V$ 'represents the evaluation value before standardization, $V_{i}$ denotes the SUWR value after standardization. The DD after standardization transformed into:

$$
D=\frac{\sum_{i=1}^{n-1} \sqrt{\left(V_{i+1}-V_{i}\right)^{2}+1^{2}}}{\sqrt{(n-0)^{2}+(n-1)^{2}}}=\frac{\sum_{i=1}^{n-1} \sqrt{\left(V_{i+1}-V_{i}\right)^{2}+1}}{\sqrt{2 n^{2}-2 n+1}}
$$


The steps for selecting the reliable SUWR evaluation method using DD theory are as below:

Step 0: Employ various methods to evaluate the level of SUWR in different regions;

Step 1: Sorting the value of SUWR assessment, then normalized it;

Step 2: Compute the DD of the SUWR among different evaluation methods using the above formula (3);

Step 3: Select the most reliable evaluation method by comparing different $D$ values.

\subsubsection{SNS theory}

Based on the theory of SNS, the ranking gained by different assessment methods are added and rearranged, then the obtained ranking of the summation of the serial number is a relatively reasonable ranking result. Thus, when an assessment method has higher relevance to relatively reasonable ranking than other methods, it can be considered to be more reasonable and stable [22].

The steps for choosing the stability SUWR assessment method using SNS theory are as below:

Step 0: Adopt various assessment methods to evaluate the SUWR in different regions and rank the assessment outcomes;

Step 1: Determine a reasonable SUWR sorting outcomes;

Step 2: Compute the Spearman correlation coefficients (SCC) between the SUWR evaluation methods sorting results and the optimal sorting;

Step 3: Analyze the stability using the method in Step 2 for many times, and select the most stable evaluation method, which compared with other methods.

The above mentioned SCC is expressed as the following:

$$
R=1-\frac{6 \times \sum H_{i}^{2}}{n\left(n^{2}-1\right)}
$$

where $H_{i}$ denotes the difference between the sorting result of the region $i$ and the reasonable sorting result; $n=9$ in this paper and it is the number of region. $R$ is the correlation coefficient, and the larger the value, the closer the result is.

The theoretical framework for the identification of the most suitable evaluation method for regional SUWR as follows (Fig. 2):

Fig. 2 The theoretical framework for selecting suitable evaluation method

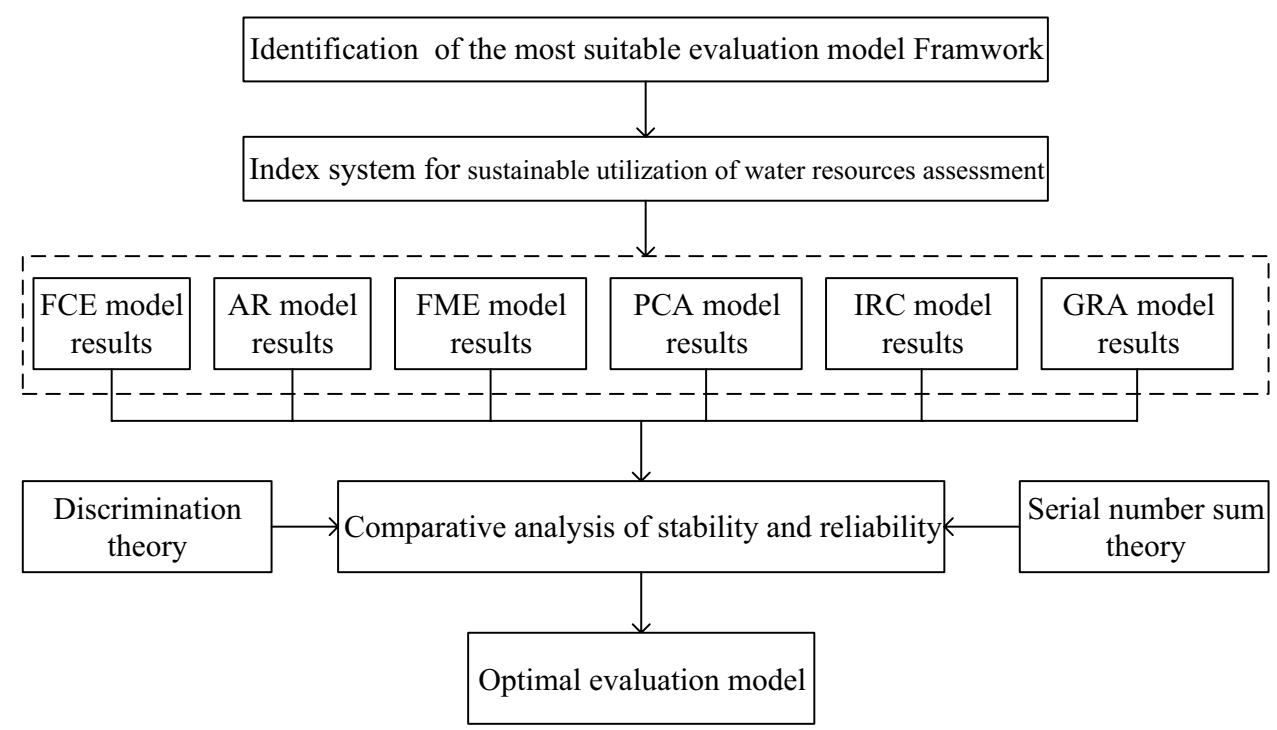


Fig. 3 Comparison of individual methods for each region of Fujian province

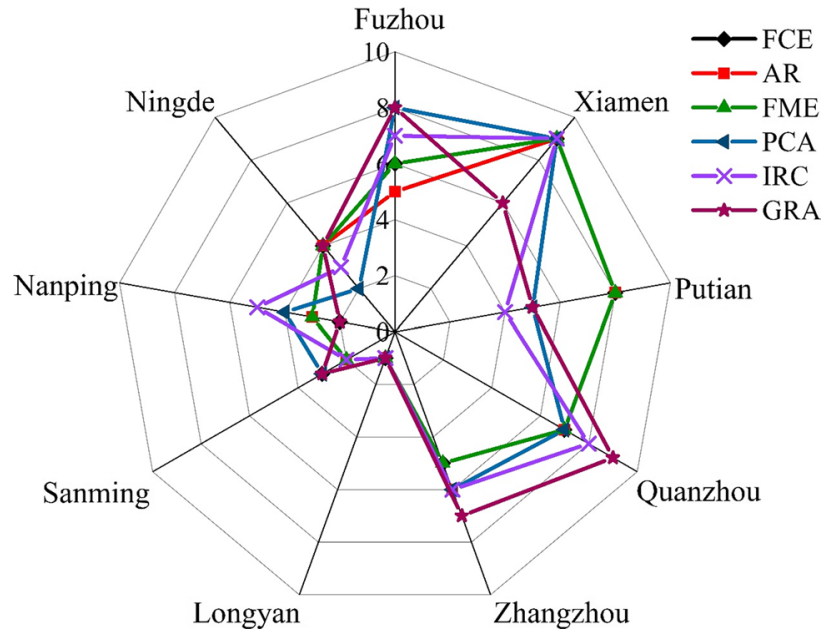

\section{Results and discussions}

\subsection{Selection of the suitable method for water resources sustainability assessment}

The assessment results in terms of ranking from frequently used evaluation methods (FCE, AR, FME, PCA, IRC and GRA) are shown in Fig. 3. Overall, there are some differences for the evaluation results of SUWR among six methods, and their differences were primarily concentrated in the southeastern districts of Fujian. Prior studies also have shown that low levels of SUWR in these areas [23]. It can be seen that six evaluation methods have different sensitivities to identify the low SUWR. For the outcomes from six assessment methods, it is difficult to determine which evaluation method is the most suitable. Thus, to improve the diagnostic level of SUWR evaluation, it is essential for selecting the suitable evaluation method of regional SUWR methods.

The reliability of each assessment method, including the FCE, AR, FME, PCA, IRC and GRA.

method, is carried out by using the DD theory based on SUWR assessment results. According to formula (2) and (3), the discrimination degree of different evaluation methods can be ranked as: $\mathrm{FME}(1.551)>\mathrm{AR}(1.543)>\mathrm{FCE}(1.468)>\operatorname{IRC}(1.16$ 1) $>P C A(1.140)>G R A(1.108)$. This shows that the discriminations belonging to the same category are similar, indicating that both of them can be considered relatively reliable. However, because FME has the highest discrimination degree, it is considered to be the most reliable.

The stability analysis of the SUWR assessment results based on SNS is shown in Table 3. The relatively reasonable ordering is highly correlated with the ranking results obtained by the FME and FCE methods, which are 0.950 and 0.933 , respectively. Nonetheless, the correlation coefficient between the relatively reasonable sorting and the GRA sorting is relatively small,

Table 3 SUWR assessment ranking from 6 methods and its optimal ranking

\begin{tabular}{llllllll}
\hline City & FCE & AR & FME & PCA & IRC & GRA & $\begin{array}{c}\text { Optimal } \\
\text { ranking }\end{array}$ \\
\hline Fuzhou & 6 & 5 & 6 & 8 & 7 & 8 & 7 \\
Xiamen & 9 & 9 & 9 & 9 & 9 & 6 & 9 \\
Putian & 8 & 8 & 8 & 5 & 4 & 5 & 6 \\
Quanzhou & 7 & 7 & 7 & 7 & 8 & 9 & 8 \\
Zhangzhou & 5 & 6 & 5 & 6 & 6 & 7 & 5 \\
Longyan & 1 & 1 & 1 & 1 & 1 & 1 & 1 \\
Sanming & 3 & 2 & 2 & 3 & 2 & 3 & 2 \\
Nanping & 2 & 3 & 3 & 4 & 5 & 2 & 3 \\
Ningde & 4 & 4 & 4 & 2 & 3 & 4 & 4 \\
Spearman correlation & 0.933 & 0.917 & 0.950 & 0.917 & 0.917 & 0.850 & - \\
coefficients & & & & & & &
\end{tabular}


Table 4 Rank correlation coefficient of each assessment method between relative reasonable sort in 25 random samples

\begin{tabular}{|c|c|c|c|c|c|c|}
\hline Method & FCE & $\mathrm{AR}$ & FME & PCA & IRC & GRA \\
\hline \multirow{25}{*}{$\begin{array}{l}\text { Spearman correlation } \\
\text { coefficients }\end{array}$} & 0.929 & 0.893 & 0.964 & 0.964 & 0.893 & 0.893 \\
\hline & 0.964 & 1.000 & 1.000 & 0.893 & 0.964 & 0.857 \\
\hline & 0.857 & 0.821 & 0.893 & 0.821 & 0.821 & 0.929 \\
\hline & 0.857 & 0.929 & 0.929 & 0.964 & 0.991 & 0.964 \\
\hline & 0.929 & 0.893 & 0.964 & 0.964 & 0.893 & 0.786 \\
\hline & 1.000 & 0.964 & 1.000 & 0.929 & 1.000 & 0.786 \\
\hline & 0.929 & 0.893 & 0.964 & 0.857 & 0.821 & 0.768 \\
\hline & 0.857 & 0.821 & 0.893 & 0.821 & 0.821 & 0.929 \\
\hline & 0.893 & 0.821 & 0.893 & 0.929 & 0.893 & 0.714 \\
\hline & 0.929 & 0.964 & 0.964 & 0.893 & 0.893 & 0.929 \\
\hline & 0.929 & 0.964 & 0.964 & 0.786 & 0.821 & 0.786 \\
\hline & 0.893 & 0.821 & 0.893 & 0.893 & 0.821 & 0.964 \\
\hline & 0.964 & 0.964 & 1.000 & 0.964 & 1.000 & 0.750 \\
\hline & 0.964 & 0.964 & 1.000 & 0.857 & 0.964 & 0.964 \\
\hline & 0.893 & 0.821 & 0.893 & 0.929 & 0.964 & 0.714 \\
\hline & 0.964 & 0.929 & 0.964 & 0.786 & 0.893 & 0.893 \\
\hline & 0.857 & 0.821 & 0.893 & 0.929 & 0.893 & 0.679 \\
\hline & 0.929 & 0.964 & 0.964 & 0.893 & 0.893 & 0.929 \\
\hline & 1.000 & 0.964 & 1.000 & 0.929 & 0.964 & 0.786 \\
\hline & 0.964 & 0.964 & 1.000 & 0.857 & 0.964 & 0.964 \\
\hline & 0.964 & 1.000 & 1.000 & 0.893 & 0.964 & 0.857 \\
\hline & 0.929 & 0.964 & 0.964 & 0.893 & 0.893 & 0.929 \\
\hline & 0.893 & 0.821 & 0.893 & 0.893 & 0.964 & 0.714 \\
\hline & 0.964 & 0.964 & 1.000 & 0.964 & 1.000 & 0.750 \\
\hline & 0.929 & 0.964 & 0.964 & 0.893 & 0.893 & 0.929 \\
\hline Summation & 23.180 & 22.888 & 23.856 & 22.394 & 22.881 & 21.163 \\
\hline Average value & 0.927 & 0.916 & 0.954 & 0.895 & 0.915 & 0.846 \\
\hline
\end{tabular}

which is 0.850 . In general, if the correlation coefficient between an assessment method and the relatively reasonable ranking results were higher than other methods, it can be considered that this method is more stable than other methods. In this study, a random sampling of six cities was selected from nine cities, the SUWR assessment for selected cities by using the above 6 methods. After 25 random sampling tests (Table 4). The analysis shows that the relatively rational ranking and the evaluation results of FME and FCE are highly correlated, which are 0.954 and 0.927 , respectively. The summations for correlation coefficient of each assessment method as below: 23.180 for the FCE method, 22.888 for the AR method, 23.856 for FME method, 22.394 for the PCA, 22.881 for the IRC method, 21.163 for the GRA method. The maximum of SCC appeared in each assessment method as follows: FCE method: 3 times; AR method: 6 times; FME method: 17 times; PCA: 4 times; IRC: 5 times; GRA: 3 times. The distribution of the lowest CC as below: FCE method: 1 time; AR method: 4 times; FME method: 0 times; PCA: 10 times; IRC: 8 times; GRA: fourteen times. It can be concluded that the stability of FME better than other methods in the SUWR assessment. According to the SNS theory, the stability ordering results can be obtained as follows: $F M E>F C E>A R>I R C>P C A>G R A$. It can be found that FME is the most stability. By combining with the analysis of reliability and stability, FME is considered to be the most reliable and stable method for SUWR evaluation among these six methods. Therefore, the fuzzy matter-element method can be considered as the suitable evaluation method for the SUWR assessment in Fujian.

\subsection{Explanation of SUWR variation in different regions based on the selected suitable method}

To obtain the comprehensive criteria for the SUWR assessment, this study used the Euclid approach degree [24] to determine the comprehensive criteria and combined with the selected suitable method. The SUWR can be classified into four levels (Table 5). From Table 6 and Fig. 4 show that in the 9 regions studied, the level of SUWR can be divided into three 
Table 5 SUWR assessment levels

\begin{tabular}{lllll}
\hline Levels & I & II & III & IV \\
\hline Boundary conditions & $\geq 0.566$ & $0.449-0.566$ & $0.346-0.449$ & $\leq 0.346$ \\
\hline
\end{tabular}

Table 6 SUWR assessment and corresponding grades in various administrative regions of Fujian province

\begin{tabular}{llll}
\hline Administrative regions & Evaluation value & Order & Levels \\
\hline Fuzhou & 0.421 & 6 & III \\
Xiamen & 0.399 & 9 & III \\
Putian & 0.414 & 8 & III \\
Quanzhou & 0.417 & 7 & III \\
Zhangzhou & 0.422 & 5 & III \\
Longyan & 0.647 & 1 & I \\
Sanming & 0.602 & 2 & I \\
Nanping & 0.577 & 3 & I \\
Ningde & 0.507 & 4 & II \\
\hline
\end{tabular}

Fig. 4 Spatial difference and grade classification of SUWR in Fujian

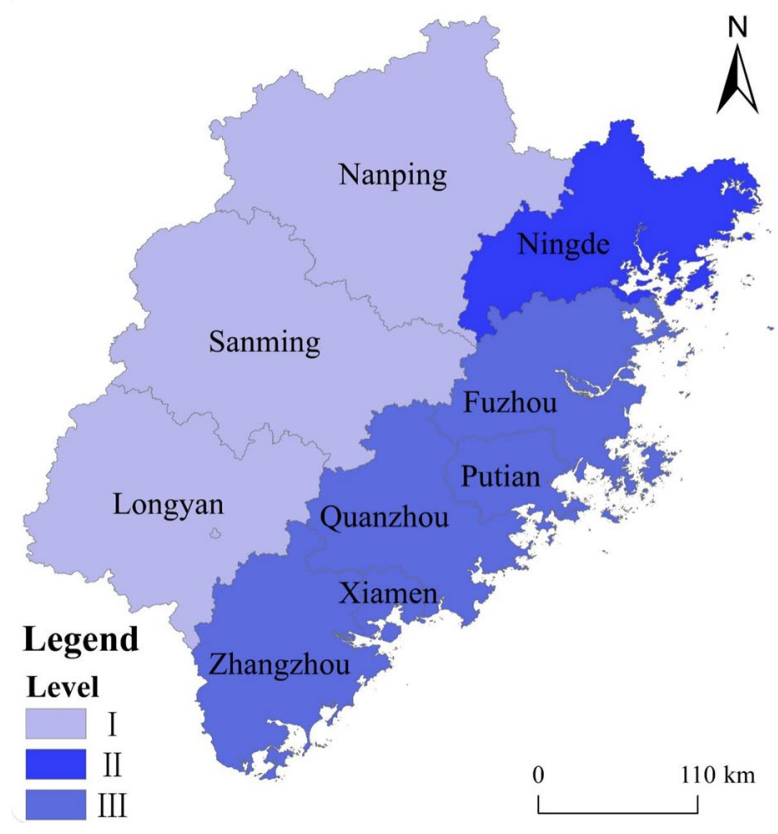

categories: The areas with SUWR at the I level were Longyan, Sanming and Nanping, and only Ningde reached level II. The administrative regions with SUWR at the level III were Fuzhou, Quanzhou, Putian, Xiamen and Zhangzhou. Table 6 shows that the different grades of SUWR in this study area was clear. The highest evaluation value was 0.647 at Longyan city, and Xiamen city has lowest value 0.399 . The regions with high SUWR were mainly distributed in the northwestern part of Fujian province, which has more precipitation and can meet the social and economic development. The water resources in southeastern Fujian are poor, the concentration of population, and the contradiction between water supply and demand is sharp. Combined with the height of the research regions (Fig. 1). The high SUWR is located in mountainous areas, indicating that topography may have a certain influence on the SUWR in the region. Therefore, cities lie in the west of Fujian should reasonably develop and utilize water resources, while cities located in the east of Fujian province need to create conditions to import water resources from other areas, otherwise the shortage of water resources will restrict the social and economic development of this region. 


\subsection{Methodological discussion}

In this study, the index weight was calculated by the subjective weighting method, it is widely used in SUWR evaluation. However, some scholars use the objective weighting method for indicators $[25,26]$, because of this method is less influenced by people. But there is also the fact that the weight of the index obtained from objective weighting method depended on the number of indicators. Figure 3 shows that the results of six assessment methods are different, so it is difficult to determine the most appropriate evaluation method, because these evaluation methods assess things from different angles. The framework can solve this problem by 2 indexes, and select the suitable evaluation method. Based on Euclid approach degree, the comprehensive standards of SUWR can be obtained on the basis of referring to relevant standards, according to which the grade of SUWR in each city can be determined. Therefore, the framework can select the evaluation method, which is suitable for the evaluation object, and provide reasonable results. The all index value can be obtained from government statistics bulletin. Considering some indicators are missing for some regions, these indicators can be converted into other indicators of SUWR. That is to say, the indicator system constructed is not specific. From this perspective, the framework proposed in this paper can be used not only for the SUWR assessment, but also for establishing an evaluation index system with good data availability. In addition, when measuring objects through multiple theoretical methods, this method can be considered to select the suitable evaluation method. Furthermore, It is worth to point out that there may be some sensitivity analysis to verify the results are more effective, we will further study in the future.

\section{Conclusions}

This study applies a framework for selecting the suitable evaluation method for the SUWR, which effectively solves the comparable problems of different assessment methods. Using the suitable method to analyze the spatial differences of SUWR in Fujian. The main conclusion are as follows:

In the evaluation of SUWR based on different evaluation methods, the stability and reliability of FME are higher than the other five methods. The SUWR in Fujian province can be divided into three categories: the I level were Longyan, Sanming and Nanping, and only Ningde reached level II, the level III were Fuzhou, Quanzhou, Putian, and Xiamen and Zhangzhou. it forms the spatial pattern of differences in sustainable use levels. The areas with higher water resources sustainable utilization are mainly distributed in the western part of the research region, good water resources conditions and good ecological environment. The lower level is in the east, where the natural endowment conditions of water resources are poor, the water demand is larger, and the contradiction between supply and demand is easier to highlight.

This study evaluated the SUWR from the regional perspective, which can provide a decision support for decisionmakers to carry out relevant policies. Because of limited information, there may be other indices and methods that may have a great influence on the SUWR assessment and need to be further studied.

Author contributions $\mathrm{XY}$ carried out all the work.

Funding There is no funding in this article.

Data availability Data sharing not applicable to this article as no datasets were generated or analysed during the current study.

Code availability Data sharing not applicable to this article as no code was generated during the current study.

\section{Compliance with ethical standards}

Competing interests The author declares no competing interests.

Open Access This article is licensed under a Creative Commons Attribution 4.0 International License, which permits use, sharing, adaptation, distribution and reproduction in any medium or format, as long as you give appropriate credit to the original author(s) and the source, provide a link to the Creative Commons licence, and indicate if changes were made. The images or other third party material in this article are included in the article's Creative Commons licence, unless indicated otherwise in a credit line to the material. If material is not included in the article's Creative Commons licence and your intended use is not permitted by statutory regulation or exceeds the permitted use, you will need to obtain permission directly from the copyright holder. To view a copy of this licence, visit http://creativecommons.org/licenses/by/4.0/. 


\section{References}

1. Goswami P, Nishad S. Quantification of regional and global sustainability based on combined resource criticality of land and water. Current Sci. 2018;114(2):355.

2. Salman DA, Amer SA, Ward FA. Water appropriation systems for adapting to water shortages in Iraq. J Am Water Resour Assoc. 2014;50:1208-25.

3. Guidolini JF, Giarolla A, Toledo PM, Valera CA, Ometto JPHB. Water sustainability at the river grande Basin, Brazil: an approach based on the barometer of sustainability. Int J Environ Res Public Health. 2018;15(11):2582.

4. Hoekstra AY, Chapagain AK, Oel PRV. Advancing water footprint assessment research: challenges in monitoring progress towards sustainable development goal 6. Water. 2017;9:438.

5. Mendoza GF, Dominique KC, et al. Sustainable water management under future uncertainty with eco-engineering decision scaling. Nat Clim Chang. 2016;6:25-34.

6. Wang R, Chen XW, Chen Y. Comparison of assessment methods for regional water resources sustainable utilization. J Nat Res. 2015;30(11):1943-55.

7. Zhang M, Zhou J, Zhou R. Evaluating sustainability of regional water resources based on improved generalized entropy method. Entropy. 2018;20(9):715.

8. Gallego-Ayala J, Juízo D. Performance evaluation of river basin organizations to implement integrated water resources management using composite indexes. Phys Chem Earth Parts A/b/c. 2012;50:205-16.

9. Kefayati M, Saghafian B, Ahmadi A, Babazadeh H. Empirical evaluation of river basin sustainability affected by inter-basin water transfer using composite indicators. Water Environ J. 2018;1:104-11.

10. Koop SHA, Leeuwen CJ. Assessment of the sustainability of water resources management: a critical review of the city blueprint approach. Water Resour Manage. 2015;29:5649-70.

11. Zhang WJ, Yu Y, Zhou XY, Yang S, Li C. Evaluating water consumption based on water hierarchy structure for sustainable development using grey relational analysis: case study in Chongqing, China. Sustainability. 2018;10(5):1538.

12. Wang Q, Li SQ, Li RR. Evaluating water resource sustainability in Beijing, China: combining PSR model and matter-element extension method. J CleanProd. 2018;206:171-9.

13. Wu XL, Hu F. Analysis of ecological carrying capacity using a fuzzy comprehensive evaluation method. Ecol Ind. 2020;113:106243.

14. Men BH, Liu HL, Wei T, Liu HL. Evaluation of sustainable use of water resources in beijing based on rough set and fuzzy theory. Water. 2017;9(11):852.

15. Yi C, Ping P, Jin JL, Li L. Water resources carrying capacity evaluation and diagnosis based on set pair analysis and improved the entropy weight method. Entropy. 2018;20(5):259.

16. Wang HR, Fan LL, Liang Y, Wang C. An integrated approach for water scarcity evaluation-a case study of Yunnan, china. Environ Dev Sustain. 2018;20(1):1-19.

17. Yang $X$, Chen $X W$. Using a combined evaluation method to assess water resources sustainable utilization in Fujian Province, China. Environ Dev Sustain. 2020. https://doi.org/10.1007/s10668-020-00939-z.

18. Baldwin C, Lewison RL, Lieske SN, Seger M, Hines E, Dearden P, Rudd MA, Jones C, Satumanatpan S, Junchompoo C. Using the DPSIR framework for transdisciplinary training and knowledge elicitation in the Gulf of Thailand. Ocean Coast Manag. 2016;134:163-72.

19. Zare F, Elsawah S, Bagheri A, Nabavi E, Jakeman AJ. Improved integrated water resource modelling by combining DPSIR and system dynamics conceptual modelling techniques. J Environ Manage. 2019;246:27-41.

20. Jia XL, Li CH, Cai YP, Wang X, Sun L. An improved method for integrated water security assessment in the Yellow River basin, China. Stoch Env Res Risk Assess. 2015;29(8):2213-27.

21. Zhang L, Li H, Liu D, Fu Q, Li M, Faiz MA, Khan ML, Li TX. Identification and application of the most suitable entropy model for precipitation complexity measurement. Atmos Res. 2019;221:89-97.

22. Liu D, Liu CL, Fu Q, Li TX, Muhammad IK, Cui S, Faiz MAELM. evaluation model of regional groundwater quality based on the crow search algorithm. Ecol Ind. 2017;81:302-14.

23. Tian HY, David BL, Gabriel TW, Mao Z, Huang Y, Xue XZ. A methodological framework for coastal development assessment: a case study of Fujian Province China. Sci Total Environ. 2017;615:572.

24. Zhang X, Meng Y, Xia J, Wu B, She DX. A combined model for river health evaluation based upon the physical, chemical, and biological elements. Ecol Ind. 2018;84:416-24.

25. Gao XP, Chen LL, Sun BW, Liu YZ. Employing SWOT analysis and normal cloud model for water resource sustainable utilization assessment and strategy development. Sustainability. 2017;9(8):1439.

26. Li S. Research on dynamic model of optimal simulation system for urban water resources sustainable utilization based on complex scientific management. Desalin Water Treat. 2018;125:156-63.

Publisher's Note Springer Nature remains neutral with regard to jurisdictional claims in published maps and institutional affiliations. 